\title{
Diferencia espacial de la incidencia de fiebre hemorrágica argentina y la composición y abundancia de roedores en el ensamble
}

María F. Piacenza', Gladys E. Calderón², Delia Enría², María C. Provensal' y Jaime J. Polop ${ }^{1}$

\footnotetext{
'Universidad Nacional de Río

Cuarto, Río Cuarto, Córdoba Argentina. Facultad de Ciencias Exactas, Físico-Químicas y Naturales. Grupo de Investigación en Ecología de Poblaciones. ${ }^{2}$ Instituto Nacional de Enfermedades Virales Humanas

"Dr. Julio I. Maiztegui", ANLIS "Dr.Carlos G. Malbrán", Pergamino, Buenos Aires, Argentina.

Este estudio se realizó en el Grupo de Investigación en

Ecología de Poblaciones, del

Departamento de Ciencias

Naturales, Facultad de Ciencias

Exactas, Físico-Químicas

Naturales, Universidad Nacional de Río Cuarto.

Declaramos no tener conflicto de intereses.

Fuente de financiamiento: Fondo para la Investigación Científica y Tecnológica (FONCYT).

Recibido: 20 de septiembre de 2017 Aceptado: 21 de abril de 2018
}

Correspondencia a: María Cecilia Provensal cprovensal@exa.unrc.edu.ar

\section{Introducción}

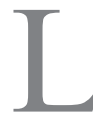
a dinámica de las enfermedades transmisibles puede ser mejor entendida en el contexto de sistemas ecológicos, dado que los hospedadores, vectores y patógenos se encuentran integrados en comunidades, interactuando con otras especies ${ }^{1-3}$. La fiebre hemorrágica argentina (FHA) es una enfermedad zoonótica, endémica en una amplia zona de la pampa húmeda de Argentina, abarcando las provincias de Buenos Aires, Córdoba, Santa Fe y La Pampa.

Su agente etiológico es el virus Junin. La enfermedad se caracteriza por presentarse en forma de brotes en el otoño y comienzo del invierno, aunque se pueden registrar casos todo el año. Las incidencias anuales por áreas son variables desde 1 a 355 casos por 100.000 habitantes para varones adultos 4 ; los niños representan $10 \%$ de los $\operatorname{casos}^{5}$. Otra característica es que cuando aparece en una zona nueva, presenta una alta incidencia durante períodos de 5-10 años, luego disminuye o desaparece y puede reemerger en zonas antiguas.

El tratamiento específico se realiza mediante la transfusión temprana de plasma inmune obtenido de personas que se han recuperado de la enfermedad, el que ha logrado reducir la letalidad de $15-30 \%$ a menos de $1 \%{ }^{6,7}$.

Desde el año 1991, la vacuna Candid I ha demostrado ser segura y efectiva para la prevención de la $\mathrm{FHA}^{8}$.

El virus Junin es mantenido en la naturaleza por el roedor Calomys musculinus ${ }^{9,10}$, el que puede presentar una infección de manera aguda o persistente sin alterar la salud de los animales infectados.

La infección natural presenta características epidemiológicas de focalidad, con registro en un sitio y ausencia en sitios cercanos.

La transmisión del virus al humano principalmente se da por contacto con las secreciones/excreciones de los roedores o aerosoles generados de las mismas ${ }^{11-13}$.

Calomys musculinus forma parte de un ensamble de roedores que comprende pocas especies ${ }^{13-15}$, y es captura- 
do predominantemente en hábitats lineales como bordes de cultivos y/o caminos ${ }^{16,17}$, con picos de abundancia en verano tardío u otoño, disminuyendo en el invierno ${ }^{16,18-19}$. Estas fluctuaciones estacionales estarían asociadas a las variaciones estacionales en la vegetación y la temperatu$\mathrm{ra}^{17,25-27}$. Asimismo, se ha establecido una sincronización del ciclo de vida de los roedores con los cultivos de verano, particularmente con el maíz ${ }^{12,20-22}$. En la región central de Argentina, C. musculinus forma parte de un ensamble de roedores junto a Akodon azarae, Necromys lasiurus y Oligoryzomys flavescens, quienes registran los máximos valores de abundancia en otoño-invierno ${ }^{11,26,28}$.

La incidencia de la FHA es variable en tiempo y espacio, lo que ha permitido reconocer tres zonas: epidémica (con alta incidencia), caracterizada por aparición y mantenimiento de casos humanos con una incidencia media mayor a 2,0/10.000 habitantes; histórica (parte del área endémica con menor incidencia), con aparición de casos humanos con una incidencia menor que 2,0/10.000 habitantes y la zona no endémica, donde no se han registrado aún casos de la enfermedad ${ }^{19,29-31}$. Estudios sobre la caracterización ambiental de las tres zonas fueron realizados por Polop y cols. ${ }^{31}$, quienes utilizaron datos ambientales obtenidos de sensores remotos y datos de precipitaciones que permitieron observar diferencias en la vegetación entre las zonas endémicas (epidémica e histórica) y no endémica de FHA y en la temperatura y precipitaciones siendo éstas mayores en la zona endémica. Estudios realizados por Piacenza ${ }^{32}$, permitieron caracterizar, en base a diferencias climáticas y ambientales, un área central y dos áreas periféricas dentro de cada zona. En relación a las variables climáticas, la zona epidémica fue registrada como una zona más cálida, con menor variación en temperatura y mayor estacionalidad en las precipitaciones que la zona histórica.

Por otra parte, respecto a variables más relacionadas al uso y manejo de la tierra, se observó que las zonas epidémica e histórica presentan mayor variación en los ciclos temporales del índice de vegetación de diferencia normalizada (NDVI), comparado con la zona no endémica. Por otro lado, Calderón y cols. ${ }^{33}$ y Polop y cols. ${ }^{31}$, registraron mayores valores de abundancia e infección por virus JUN en C. musculinus capturados en la zona epidémica.

Las zonas epidémica, histórica y no endémica presentan variaciones en las características epidemiológicas, la abundancia del hospedador y las condiciones climáticas y ambientales de cada una de ellas. Mills y Childs ${ }^{34}$ y Mills y cols. ${ }^{35}$ han propuesto que el riesgo de adquirir una enfermedad zoonótica depende de la densidad poblacional del hospedador y que dicha densidad se encuentra influenciada por características del ambiente, tanto bióticas (calidad y disponibilidad de hábitat) como físicas (variables climáticas, condiciones edáficas, etc.). Asumiendo este modelo de interacciones entre los componentes del ecosistema, las diferencias en la incidencia de FHA podrían deberse, tanto a la relación virus-hospedador-humanos, como a la correspondencia de alguno/s de estos tres componentes con las condiciones climáticas y ambientales.

Ostfeld y Keesing ${ }^{36}$ sostienen que, en comunidades constituidas por pocas especies, el riesgo de contraer la enfermedad puede estar estrechamente vinculado a la abundancia del hospedador. De esta manera, la infección se vería favorecida por la mayor frecuencia de contacto entre los hospedadores inducida por su alta abundan$\mathrm{cia}^{37,38}$. Se ha postulado que incrementos en la diversidad y abundancia de las especies que no son hospedadoras del patógeno en un determinado ensamble reducirían, por interferencia, los números de encuentros entre los potenciales hospedadores, influenciando así en la tasa de transmisión del virus ${ }^{2}$. Por lo tanto, estudiar la composición del ensamble de roedores y abundancia relativa de cada especie en las distintas zonas de incidencia de la FHA, permitiría avanzar en los posibles determinantes ecológicos de la distribución espacial del virus JUN en las poblaciones de su hospedador.

En el presente trabajo, los objetivos planteados fueron:

- Caracterizar y comparar la composición y diversidad de los ensambles de pequeños mamíferos dentro de las zonas epidémica, histórica y no endémica de FHA.

- Estimar la abundancia de C. musculinus en cada una de estas zonas.

- Determinar la presencia de infección por virus Junin en las poblaciones de C. musculinus de cada zona.

- Relacionar la composición de los ensambles de roedores y la abundancia de C. musculinus dentro y entre zonas con diferente incidencia de la enfermedad.

\section{Material y Método}

La región de estudio se ubica en el centro de Argentina (Figura 1), habiéndose considerado las zonas con diferente incidencia de $\mathrm{FHA}^{29}$ a partir de los mapas elaborados por Piacenza ${ }^{32}$ en relación a variables ambientales. En cada una de esas zonas se demarcó un área central y dos áreas periféricas en función de las diferencias ambientales registradas por Piacenza ${ }^{32}$. Las áreas periféricas se ubicaron en los límites de cada zona con las restantes, en tanto que las áreas centrales en el interior de cada zona. Así, 18 áreas rurales fueron seleccionadas para realizar los muestreos durante dos años (nueve por año). En cada área se seleccionaron tres sitios diferentes en los que se realizó captura por remoción a través de trampas de captura viva tipo "Sherman", ubicadas en líneas de 100 $\mathrm{m}$ durante tres noches consecutivas. Cada línea de captura estuvo constituida por 20 trampas, ubicadas en bordes de cultivos, a un intervalo de $5 \mathrm{~m}$ entre ellas. Las mismas 


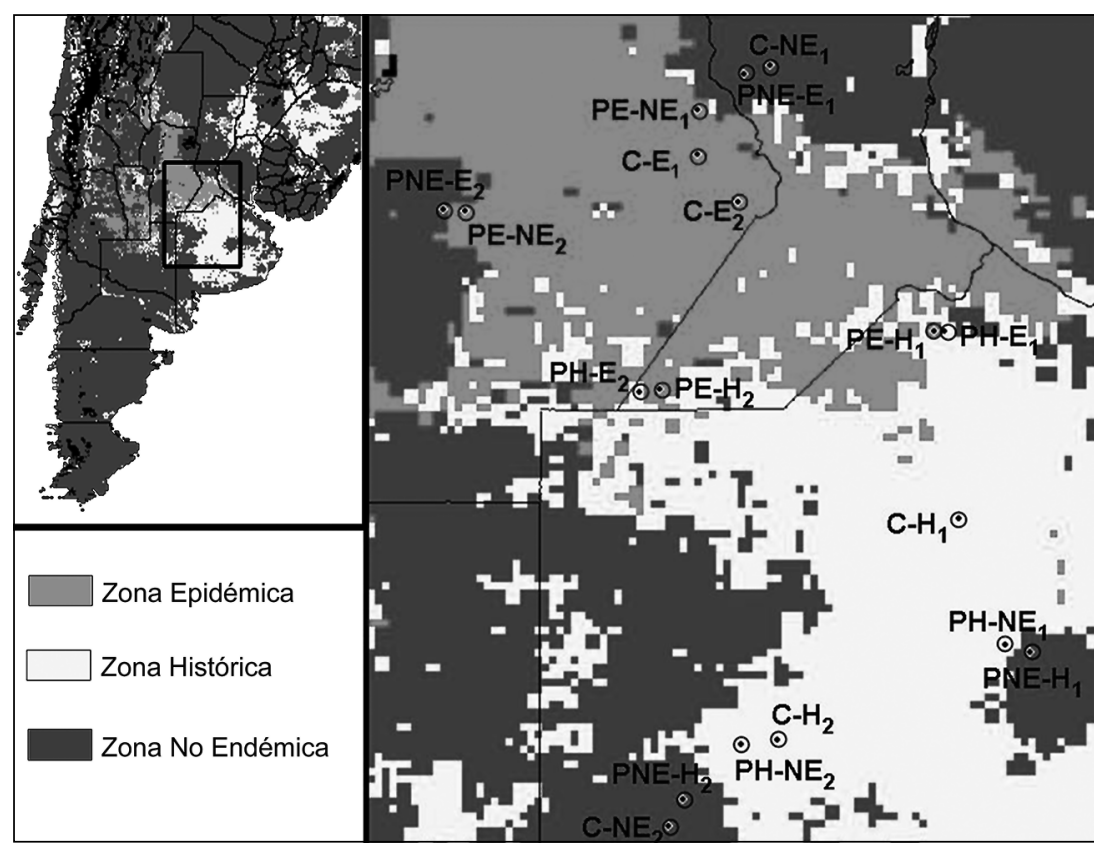

Figura 1. Ubicación del área de estudio en región central de Argentina y de los sitios de muestreo para los dos períodos de captura, por área en la zona de estudio (subíndice 1: otoño 2007; subíndice 2: otoño 2008). C-NE: Central-No endémica; PNE-E: Periférica No endémica-Epidémica; PE-NE: Periférica Epidémica-No endémica; C-E: Central-Epidémica; PE-H: Periférica Epidémica-Histórica; PH-E: Periférica Histórica-Epidémica; C-H: Central Histórica; PH-NE: Periférica Histórica-No endémica; PNE-H: Periférica No endémica-Histórica.

fueron cebadas con una mezcla de grasa vacuna y pasta de maní. Los muestreos de roedores se llevaron a cabo durante la estación de otoño de los años 2007 y 2008.

En otoño de 2007 se seleccionaron como áreas centrales epidémica, histórica y no endémica, sitios de las localidades de Leones (Provincia de Córdoba), Bragado (Provincia de Buenos Aires) y Carlos Pellegrini (Provincia de Santa $\mathrm{Fe}$ ), respectivamente. Como área periférica epidémica-no endémica, sitios de la localidad de Noetinger (Provincia de Córdoba); como área periférica no endémica-epidémica, sitios de Piamonte (Provincia de Santa $\mathrm{Fe}$ ); como áreas periférica histórica-no endémica y periférica no endémica-histórica, sitios de General Alvear (Provincia de Buenos Aires) y finalmente, como periférica histórica-epidémica y periférica epidémicahistórica, sitios de la localidad de Pergamino (Provincia de Buenos Aires).

En el año 2008, se seleccionaron sitios de las localidades de Los Surgentes (Provincia de Córdoba), Daireaux (Provincia de Buenos Aires) y Caruhé (Provincia de Buenos Aires), los que fueron seleccionados como áreas centrales de las zonas epidémica, histórica y no endémica, respectivamente. Sitios de la localidad de Amenábar (Provincia de Santa $\mathrm{Fe}$ ) fueron elegidos en representación del área periférica epidémica-histórica; y sitios de la localidad de Olaeta (Provincia de Córdoba) se correspondieron al área periférica epidémica-no endémica. En la proximidad a las localidades de Rufino (Provincia de Santa Fe) se ubicaron los sitios de captura correspondientes al área periférica histórica-epidémica y sitios de Daireaux se asignaron al área periférica histórica-no endémica. Por último, sitios de las localidades de Charras (Provincia de Córdoba) y Guaminí (Provincia de Buenos Aires) fueron seleccionados para realizar las capturas correspondientes a las áreas periférica no endémica-epidémica y periférica no endémica-histórica.

Las líneas de captura fueron revisadas diariamente, reemplazando las trampas que poseían capturas por una trampa vacía. En el laboratorio de campo se procedió al procesamiento de los roedores, los que fueron anestesiados por inhalación de isofluorano, registrando especie, sexo, estado reproductivo, peso, largo total, largo de cola, pata y oreja y presencia de heridas. Todos los individuos capturados vivos fueron sangrados a partir del seno retro-orbital. Posteriormente se realizó la eutanasia por sobredosis de anestesia, previo a realizarse la necropsia. De los roedores de la especie C. musculinus se obtuvo además una muestra de cerebro siendo conservadas en nitrógeno líquido y trasladadas al Instituto Nacional de Enfermedades Virales Humanas (INEVH) donde se ingresaron a congeladores de $-70^{\circ} \mathrm{C}$. Las muestras de sangre de los C. musculinus fueron estudiadas por la técnica de ELISA de acuerdo a lo descrito por Morales y cols. ${ }^{39}$, para detectar la presencia de anticuerpos IgG anti-virus Junin. En una porción de cerebro se realizó la extracción del ácido ribonucleico (ARN) viral utilizando el kit Qiamp Viral RNA Mini Kit (Qiagen Inc., Germany). La amplificación del genoma se realizó mediante una reacción de polimerasa en cadena-transcriptasa reversa (RPC-TR) anidada "in house" utilizando un set de oligonucleótidos genéricos para arenavirus que amplifica un fragmento de $600 \mathrm{nt}$ del gen de la nucleoproteina. Sobre este producto de amplificación, se realizó una segunda corrida con un set de oligonucleótidos específicos para virus JUN que amplifican un fragmento de 150 nucleótidos.

La captura y manipulación de roedores se realizó siguiendo las normativas de la Sociedad Americana de Mastozoología para el uso de mamíferos silvestres en la investigación ${ }^{40} \mathrm{y}$ bajo normas de bioseguridad de acuerdo a lo recomendado por el Centro para el Control y Prevención de Enfermedades (CDC) ${ }^{41,42}$, Atlanta, E.U.A., y de acuerdo a las normas nacionales e internacionales de la Asociación Argentina para el estudio de los mamíferos (www.sarem.org.ar).

Los ensambles de pequeños roedores se describieron a través del porcentaje que representó cada especie en el mismo. Se comparó la abundancia entre zonas con distinta incidencia de FHA, entre las áreas dentro de cada zona y entre áreas pertenecientes a diferentes zonas, mediante la 
utilización de un modelo de análisis de varianza anidado (ANOVA). El factor "entre" fueron las tres zonas y el factor "anidado" fueron las tres áreas dentro de cada zona.

Dado que se realizó el mismo esfuerzo de captura por zonas y por áreas dentro de cada zona, para comparar la abundancia se utilizó como variable respuesta el número absoluto de capturas por línea de trampas, considerando cada sitio (línea) como réplica dentro de un área $(\mathrm{n}=3)$. Cuando las diferencias entre zonas y entre áreas fueron significativas se aplicó el test a posteriori pareado de Student-Newman-Keuls (S.N.K). El análisis estadístico se llevó a cabo mediante el programa InfoStat ${ }^{43}$.

La prevalencia de infección por virus Junin en $C$. musculinus fue calculada como el número de animales positivos dividido por el número total de animales estudiados y multiplicado x 100 .

\section{Resultados}

Durante el estudio se capturaron 1.407 roedores a través de un esfuerzo de captura de 9.720 trampas-noche. En el año 2007 se capturaron 829 individuos, pertenecientes a nueve especies (Tabla 1). En las zonas epidémica e histórica se registró una mayor proporción de individuos dentro de las áreas centrales, mientras que en la zona no endémica el mayor número de individuos se registró en el área periférica (Figura 2). En el año 2008 se capturaron 578 individuos, pertenecientes a nueve especies, en su mayoría registradas el año anterior (Tabla 2). De este total, 203 individuos fueron capturados en la zona epidémica, 196 fueron capturados en la zona histórica y 179 en zona no endémica de FHA (Tabla 2). En las zonas epidémica e histórica se registró una mayor proporción de individuos

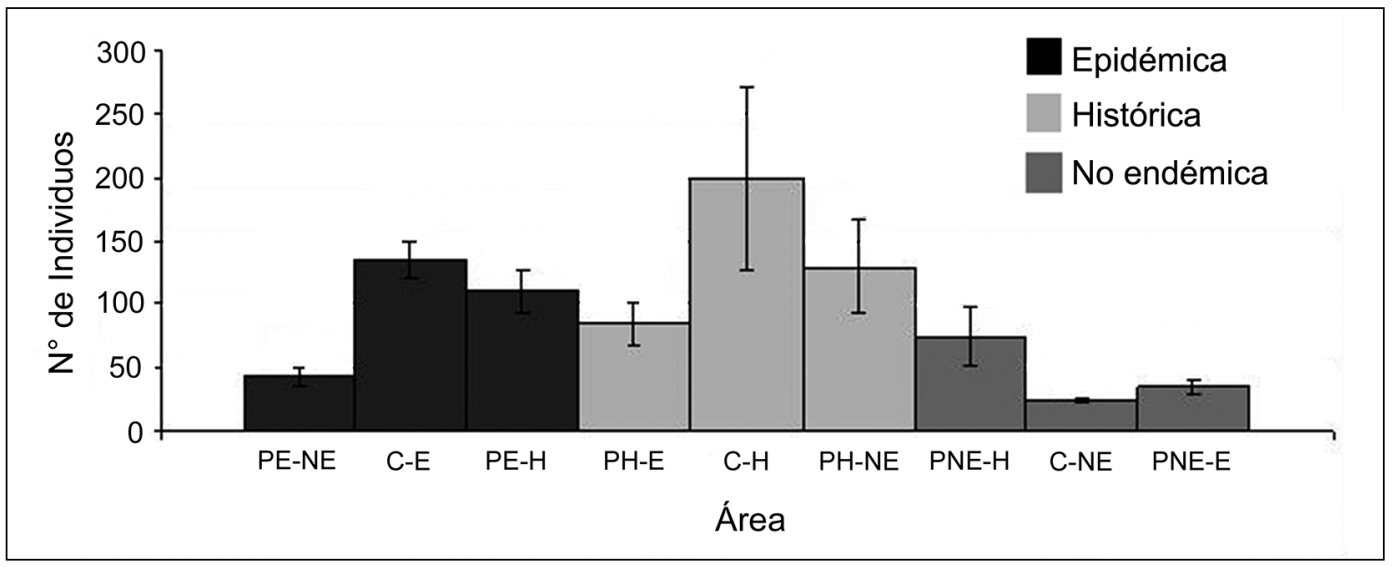

Figura 2. Número de roedores capturados por área dentro de cada zona de incidencia de Fiebre Hemorrágica Argentina en otoño de 2007. C-NE: Central-No endémica; PNE-E: Periférica No endémica-Epidémica; PE-NE: Periférica Epidémica-No endémica; C-E: Central-Epidémica; PE-H: Periférica Epidémica-Histórica; $\mathrm{PH}-\mathrm{E}$ : Periférica Histórica-Epidémica; C: Central Histórica; PH-NE: Periférica Histórica-No endémica; PNE-H: Periférica No endémica-Histórica. Las barras representan el desvio estándar para cada área y el número de repeticiones para calcularlo fue " $n "=3$.

\begin{tabular}{|c|c|c|c|c|c|c|c|c|c|c|c|c|c|}
\hline \multirow{2}{*}{$\begin{array}{l}\text { Zona } \\
\text { Área } \\
\text { Especie }\end{array}$} & \multicolumn{4}{|c|}{ Epidémica } & \multicolumn{4}{|c|}{ Histórica } & \multicolumn{4}{|c|}{ No endémica } & \multirow{2}{*}{$\begin{array}{l}\text { Total genera } \\
\text { por especie }\end{array}$} \\
\hline & PE-H & C-E & PE-NE & $\begin{array}{c}\text { Total } \\
\text { epidémica }\end{array}$ & PH-E & $\mathrm{C}-\mathrm{H}$ & PH-NE & $\begin{array}{c}\text { Total } \\
\text { histórica }\end{array}$ & PNE-E & C-NE & PNE-H & $\begin{array}{l}\text { Total no } \\
\text { endémica }\end{array}$ & \\
\hline A. azarae & 25 & 14 & 6 & 45 & 12 & 167 & 96 & 275 & 16 & 2 & 53 & 71 & 391 \\
\hline A. dolores & 0 & 11 & 0 & 11 & 0 & 0 & 0 & & 0 & 0 & 0 & & 11 \\
\hline C. laucha & 4 & 25 & 2 & 31 & 2 & 2 & 4 & 8 & 2 & 4 & 3 & 9 & 48 \\
\hline C. musculinus & 51 & 47 & 21 & 119 & 48 & 22 & 20 & 90 & 7 & 5 & 13 & 25 & 234 \\
\hline M. musculus & 0 & 22 & 1 & 23 & 5 & 0 & 0 & 5 & 0 & 0 & 0 & 0 & 28 \\
\hline N. lasiurus & 11 & 2 & 0 & 13 & 6 & 0 & 2 & 8 & 7 & 6 & 0 & 13 & 34 \\
\hline O. flavescens & 15 & 12 & 5 & 32 & 10 & 7 & 7 & 24 & 3 & 6 & 5 & 14 & 70 \\
\hline
\end{tabular}

PE-H: Periférica Epidémica-Histórica; C-E: Central Epidémica; PE-NE: Periférica Epidémica-No endémica; PH-E: Periférica Histórica-Epidémica; C-H Central Histórica; PH-NE: Periférica Histórica-No endémica; PNE-E: Periférica No endémica-Epidémica; C-NE: Central No endémica; PNE-H: Periférica No endémica-Histórica. 
Tabla 2. Número de individuos capturados en otoño de 2008 por especie, zona, área, y total general para las zonas con distinta incidencia de fiebre hemorrágica argentina

\begin{tabular}{|c|c|c|c|c|c|c|c|c|c|c|c|c|c|}
\hline \multirow{2}{*}{$\begin{array}{l}\text { Zona } \\
\text { Área } \\
\text { Especie }\end{array}$} & \multicolumn{4}{|c|}{ Epidémica } & \multicolumn{4}{|c|}{ Histórica } & \multicolumn{4}{|c|}{ No endémica } & \multirow{2}{*}{$\begin{array}{l}\text { Total general } \\
\text { por especie }\end{array}$} \\
\hline & PE-H & C-E & PE-NE & $\begin{array}{c}\text { Total } \\
\text { epidémica }\end{array}$ & PH-E & $\mathrm{C}-\mathrm{H}$ & PH-NE & $\begin{array}{c}\text { Total } \\
\text { histórica }\end{array}$ & PNE-E & C-NE & PNE-H & $\begin{array}{l}\text { Total no } \\
\text { endémica }\end{array}$ & \\
\hline A. azarae & 10 & 28 & 27 & 65 & 28 & 61 & 53 & 142 & 22 & 6 & 11 & 39 & 246 \\
\hline C. aperea & 0 & 1 & 0 & 1 & 0 & 0 & 0 & 0 & 1 & 0 & 0 & 1 & 2 \\
\hline C. laucha & 8 & 5 & 3 & 16 & 1 & 5 & 4 & 10 & 3 & 1 & 0 & 4 & 30 \\
\hline C. musculinus & 20 & 20 & 37 & 77 & 5 & 14 & 21 & 40 & 40 & 12 & 18 & 70 & 187 \\
\hline C. venustus & 0 & 0 & 13 & 13 & 0 & 0 & 0 & 0 & 12 & 0 & 0 & 12 & 25 \\
\hline M. musculus & 0 & 6 & 0 & 6 & 1 & 0 & 1 & 2 & 0 & 29 & 17 & 46 & 54 \\
\hline N. lasiurus & 0 & 8 & 0 & 8 & 0 & 0 & 0 & 0 & 0 & 0 & 1 & 1 & 9 \\
\hline O. flavescens & 1 & 3 & 1 & 5 & 0 & 2 & 0 & 2 & 4 & 0 & 0 & 4 & 11 \\
\hline O. rufus & 0 & 0 & 12 & 12 & 0 & 0 & 0 & 0 & 2 & 0 & 0 & 2 & 14 \\
\hline Total de roedores & 39 & 71 & 93 & 203 & 35 & 82 & 79 & 196 & 84 & 48 & 47 & 179 & 578 \\
\hline
\end{tabular}

Figura 3. Número de roedores capturados por área dentro de cada zona de incidencia de Fiebre Hemorrágica Argentina en otoño de 2008. C-NE: Central-No endémica; PNE-E: Periférica No endémicaEpidémica; PE-NE: Periférica Epidémica-No endémica; C-E: Central-Epidémica; PE-H: Periférica Epidémica-Histórica; PH-E: Periférica Histórica-Epidémica; C: Central Histórica; PH-NE: Periférica Histórica-No endémica; PNE-H: Periférica No endémicaHistórica. Las barras representan el desvio estándar para cada área y el número de repeticiones para calcularlo fue " $n "=3$.

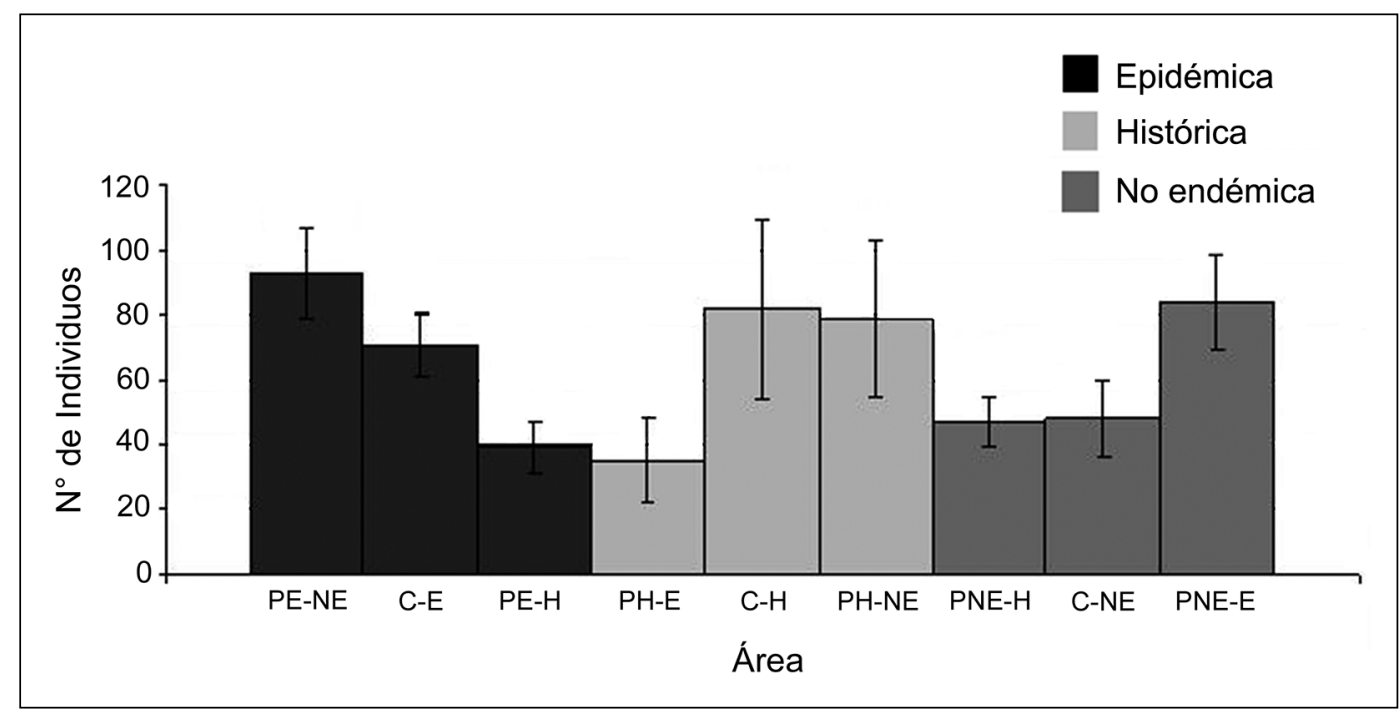

en sus áreas centrales y periféricas que en las áreas no endémicas, mientras que en la zona no endémica el mayor número de individuos se registró en el área periférica al área epidémica (Figura 3).

Los resultados mostraron diferencias significativas entre las zonas para la abundancia total de roedores correspondientes al año $2007\left(\mathrm{~F}_{(2,6)}=11,60 ; \mathrm{p}=0,006\right)$. El mayor registro de abundancia en las dos primeras zonas se obtuvo en las áreas centrales y en las periféricas que limitaban con la zona no endémica, en tanto que en la no endémica se capturaron más individuos en el área central y en la periférica que limitaba con la zona histórica.

Considerando las áreas dentro de cada zona, también existieron diferencias significativas entre algunas de ellas. En la zona epidémica hubo diferencias significativas entre el área periférica epidémica-no endémica y las áreas central y periférica epidémica-histórica $\left(\mathrm{F}_{(2,6)}=9,17\right.$; $\mathrm{p}=0,015)$, siendo menor la abundancia en el área periférica epidémica-no endémica. En relación a la zona histórica, no existieron diferencias significativas en la 
abundancia $\left(\mathrm{F}_{(2,6)}=2,47 ; \mathrm{p}=0,165\right)$. Por último, en las áreas correspondientes a la zona no endémica, se encontraron diferencias significativas entre el área periférica no endémica-histórica y las áreas central y periférica no endémica-epidémica $\left(\mathrm{F}_{(2,6)}=8,45 ; \mathrm{p}=0,018\right)$, con mayores valores de abundancia en la periférica no endémicahistórica. En el año 2008, sólo se encontraron diferencias significativas en la zona epidémica entre el área periférica epidémica-histórica y periférica epidémica- no endémica $\left(\mathrm{F}_{(2,6)}=5,8 ; \mathrm{p}=0,009\right)$.

En el año 2007 se capturaron 234 individuos de C. musculinus (Tabla 1) y el análisis mostró diferencias significativas entre las tres zonas $\left(\mathrm{F}_{(2,72)}=13,97\right.$; $\mathrm{p}<0,0001)$. No se encontraron diferencias significativas en la abundancia de C. musculinus entre las áreas dentro de la zona epidémica $\left(\mathrm{F}_{(2,24)}=3,09 ; \mathrm{p}=0,064\right)$, de la zona histórica $\left(\mathrm{F}_{(2,24)}=0,95 ; \mathrm{p}=0,401\right)$ o de la zona no endémica $\left(\mathrm{F}_{(2,24)} \stackrel{(2,24)}{=} 1,41 ; \mathrm{p}=0,263\right)$. Al analizar entre áreas de distintas zonas, se observó que la abundancia del hospedador fue significativamente mayor en las áreas centrales de la zonas epidémica e histórica, respecto a la central de la zona no endémica $\left(\mathrm{F}_{(2,24)}=12,7 ; \mathrm{p}=0,0001\right)$. La comparación de las áreas periféricas entre zonas con distinta incidencia registró diferencias significativas para las epidémica-no endémica y no endémica-epidémica $\left(\mathrm{F}_{(1,16)}=5,76 ; \mathrm{p}=0,029\right)$, siendo más abundante en la primera, y no registró diferencias para las áreas periféricas epidémica-histórica e histórica-epidémica $\left(\mathrm{F}_{(1,16)}=0,30\right.$; $\mathrm{p}=0,594)$ y no endémica-histórica e histórica-no endé$\operatorname{mica}\left(\mathrm{F}_{(1,16)}=0,65 ; \mathrm{p}=0,432\right)$.

En 2008, las capturas de C. musculinus fueron menos frecuentes, registrándose un total de 187 individuos (Tabla 2) y la abundancia de C. musculinus no mostró diferencias significativas entre las zonas con diferente incidencia de FHA $\left(\mathrm{F}_{(2,72)}=1,82 ; \mathrm{p}=0,170\right)$. Tampoco hubo diferencias significativas entre las áreas dentro de las zonas (epidémica: $\mathrm{F}_{(2,24)}=1,66 ; \mathrm{p}=0,211$; histórica: $\mathrm{F}_{(2,24)}=2,26$; $\mathrm{p}=0,127$, y no endémica: $\left.\mathrm{F}_{(2,24)}=2,31 ; \mathrm{p}=0,121\right)$, ni entre las áreas centrales de las zonas $\left(\mathrm{F}_{(2,24)}=0,03 ; \mathrm{p}=0,968\right)$. En 2008 sólo se registraron diferencias marginales entre las áreas periférica epidémica-histórica e históricaepidémica $\left(\mathrm{F}_{(1,16)}=4,33 ; \mathrm{p}=0,054\right)$, siendo mayor la abundancia en la primera. No se registraron diferencias en la abundancia de C. musculinus entre las otras áreas periféricas (valores $\mathrm{p}=0,937 \mathrm{y} \mathrm{p}=0,725$ ).

En general, las dos especies más abundantes fueron $A$. azarae y C. musculinus en ambos años. En el año 2007 se observaron diferencias significativas entre la abundancia de estas dos especies, siendo mayor la abundancia de C. musculinus en la zona epidémica $\left(\mathrm{F}_{(1,52)}=15,22\right.$; $\mathrm{p}=0,000)$, mientras que $A$. azarae predominó en la zona histórica $\left(\mathrm{F}_{(1,52)}=11,22 ; \mathrm{p}=0,002\right)$. En el año 2008 sólo se registraron diferencias significativas entre estas especies en la zona histórica, donde fue mayor la abundancia de
A. azarae (histórica $\mathrm{F}_{(1,52)}=13,30 ; \mathrm{p}=0,001$; epidémica $\mathrm{F}_{(1,52)}=0,34 ; \mathrm{p}=0,562$; no endémica $\mathrm{F}_{(1,52)}=3,15$; $\mathrm{p}=0,082)$.

Los resultados de las 368 muestras de sangre de $C$. musculinus capturados en los dos años de estudio y estudiadas por ELISA resultaron negativas. Los estudios moleculares realizados en 363 muestras de cerebro permitieron detectar la presencia de ARN viral en individuos capturados en las zonas epidémicas: en el año 2007, se obtuvo una prevalencia de infección de 2,7\% (3/110) y en el año 2008 fue de 1,1\% (1/87), no detectándose infección en las zonas histórica y no endémica durante los dos años de estudio.

\section{Discusión}

En general se observó una correspondencia entre los valores de mayor abundancia de C. musculinus y su predominio en el ensamble con la zona de mayor incidencia de la enfermedad, similar a lo registrado por otros autores $^{30,33}$. Calomys musculinus fue más abundante en la zona epidémica y $A$. azarae en la histórica. Nuestros resultados concuerdan con los antecedentes obtenidos en muestreos de localidades con distinta incidencia de la enfermedad. Crespo y cols. ${ }^{28}$, y Sabattini y cols. ${ }^{10}$, registraron una relación similar, con mayor abundancia de C. musculinus dentro de los sitios de zona epidémica, en comunidades de Laboulaye, provincia de Córdoba, de la misma manera que Mills y cols. ${ }^{19}$ y Ellis y cols. ${ }^{15}$ lo observaron en comunidades de las localidades de Alcorta, Arteaga, Bigand, Casilda, General Gelly, Máximo Paz, San José y J.B. Molina, en provincia de Santa Fe. A su vez, la mayor representatividad de $A$. azarae en la zona histórica ya había sido registrada en otras localidades en la provincia de Buenos Aires, como Azul, Melo, Pergamino, Rojas y Zárate ${ }^{19,26,28,33}$. En la zona no endémica se registró baja abundancia y dominancia numérica, tanto de A. azarae como de C. musculinus, dependiendo del año y localidades muestreadas en cada uno. En las localidades de Oliveros y Maciel, provincia de Santa Fe, y en Gualeguay (Entre Ríos) se registró una dominancia numérica de A. azarae ${ }^{33}$, y en localidades de la Provincia de Córdoba la dominancia numérica correspondió a $C$. musculinus $^{19,44-46}$.

De esta manera, aunque la generalización que realizáramos sobre la estructura del ensamble de cada zona proviene de registros puntuales realizados en pocas localidades (considerando la gran extensión que abarca la región estudiada), los resultados obtenidos coinciden con los registros de otros autores en localidades definidas sólo en base a la epidemiología de la enfermedad. Esta diferencia aportaría la idea que el predominio numérico y la alta abundancia del hospedador influirían en la dife- 
rencia de la incidencia de la enfermedad entre zonas. Los resultados de este estudio son coherentes con la premisa que la permanencia y la prevalencia de la infección podrían estar asociadas a la representatividad numérica de C. musculinus en el ensamble ${ }^{30,47}$. La mayor abundancia registrada en la zona epidémica de $C$. musculinus respecto a las otras zonas, donde esta especie triplica a $A$. azarae es coherente con dicha premisa. En este sentido, Busch y Hodara $^{48}$ postularon que $A$. azarae es una especie competitivamente dominante sobre las otras especies del ensamble y que el efecto de esta competencia no es lineal, sino que existe un valor umbral a partir del cual la abundancia de las otras especies disminuye.

Así, estas relaciones de dominancia podrían afectar la abundancia del hospedador y/o reducir la tasa de contacto entre los individuos susceptibles e infectados, influenciando la tasa de transmisión del virus. Este postulado concuerda con lo propuesto por Keesing y cols. ${ }^{2}$, donde el "efecto dilución" de una enfermedad ocurre mediante el mecanismo de reducción de encuentros, mediado por la abundancia de especies que no son hospedadores del patógeno. En este estudio no es posible atribuir a alguna de ellas como la responsable de la diferencia espacial del riesgo, permitiendo sólo reconocer resultados que son coherentes con aquella hipótesis.

En síntesis, en este sistema, la abundancia de $C$. musculinus podría estar influenciando la dinámica del patógeno, más que la diversidad total del ensamble per se o la presencia de $A$. azarae. Ello basado en que en la zona epidémica es donde se registra el hospedador permanentemente en alta abundancia, con diferencias significativas al compararse con la zona no endémica, a pesar de la presencia de $A$. azarae en altos números y que, en la zona histórica, la abundancia del hospedador es menor, aunque no difiera significativamente con la epidémica, alternando el predominio con $A$. azarae. Para algunos autores ${ }^{30,47}$ la diferencia en la abundancia de C. musculinus puede ser la responsable de la variación espacial en el riesgo o la incidencia de la enfermedad. Así, el riesgo de la población humana a enfermarse será mayor en aquellos casos donde el hospedador sea lo suficientemente abundante para transmitir y mantener el virus a través del contacto roedor-roedor, comparado con comunidades donde sus valores de abundancia no permitan la subsistencia del mismo ${ }^{30,49-50}$. Así, el aumento de la proporción de interacciones inter-específicas resultaría en una disminución de la incidencia y prevalencia en la especie hospedadora. Alta diversidad y altos valores de abundancia de roedores no hospedadores pueden diluir el impacto de la FHA, reduciendo las interacciones entre co-específicos de C. musculinus y el consecuente riesgo a enfermar. Una situación similar en la enfermedad de Lyme fue denominada como "efecto de dilución" por Ostfeld y Keesing ${ }^{36}$.
En relación a la infección y considerando estudios realizados por Vitullo y cols. ${ }^{51}$, en C. musculinus infectados experimentalmente con virus JUN que demostraron dos tipos de respuesta a la infección: aguda con producción de anticuerpos y eliminación del virus; persistente con ausencia o bajos títulos de anticuerpos, viremia crónica y virus en cerebro, órganos linfáticos y viscerales, podemos inferir que los resultados de infección obtenidos en este trabajo estarían indicando que al momento de la captura, los animales infectados estaban cursando una infección persistente con posibilidad de transmisión del agente viral.

La prevalencia de infección obtenida en este trabajo fue semejante a la registrada en estudios previos para la zona epidémica ${ }^{29,30}$. La presencia de infección en determinadas áreas y ausencia en otras pondría de manifiesto la presencia de focos de infección detectados durante el muestreo realizado ${ }^{52,53}$. Los límites de las zonas con distinta incidencia de la enfermedad no serían estáticos ya que el virus podría expandir su distribución a partir de la transmisión de poblaciones contiguas. De esta manera, la dinámica del sistema virus-hospedador probablemente dirigida por la abundancia del hospedador, determinaría que el ciclo de la infección se mantenga o no.

Agradecimientos. Esta investigación tuvo apoyo económico del Fondo para la Investigación Científica y Tecnológica (FONCYT). Agradecemos los valiosos aportes y comentarios de los revisores anónimos y del Comité Editorial, para mejorar el trabajo. A Germán O’Duyer, José Paura y César Polidoro por el apoyo técnico para la captura y procesamiento de roedores silvestres.

\section{Resumen}

La fiebre hemorrágica argentina (FHA) es una enfermedad zoonótica endémica en una amplia zona de la pampa húmeda de Argentina. El agente etiológico es el virus Junin que es mantenido en la naturaleza por el roedor Calomys musculinus y transmitido, principalmente, al humano a través de aerosoles generados de las secreciones y excreciones. Objetivos: Caracterizar la composición y diversidad de los ensambles de pequeños roedores, determinar la abundancia del hospedador C. musculinus y la prevalencia del virus de la FHA en las zonas epidémica, histórica y no endémica de dicha enfermedad en Argentina. Métodos: Para el muestreo de roedores en cada una de las zonas se demarcaron un área central y dos periféricas para 18 localidades de la región central de Argentina (incluyendo las provincias de Córdoba, Buenos Aires y Santa Fe) muestreadas en dos años. Se comparó la abundancia de C. musculinus entre zonas y entre las áreas dentro de cada zona y áreas cercanas entre zonas, utilizan- 
do modelos de análisis de varianza anidados. Resultados. Dentro de cada zona, el ensamble de roedores mostró diferencia espacial en la composición específica, diversidad y abundancia de C. musculinus. La zona epidémica registró mayor número de especies y mayor abundancia del hospedador. En zona histórica se capturó el menor número de especies (de roedores) y Akodon azarae fue la más abundante. En zona no endémica la composición del ensamble y la abundancia de C. musculinus variaron entre los dos años. Sólo se detectó infección por virus Junin en $C$. musculinus correspondientes a la zona epidémica con una prevalencia de 2,7 y $1,1 \%$ para los años 2007 y 2008, respectivamente. Conclusión: En este sistema, la abundancia del hospedador estaría afectando la dinámica espacial de este virus, más que la diversidad del ensamble o la presencia de $A$. azarae.

\section{Referencias bibliográficas}

1.- Ostfeld R, Glass G, Keesing F. Spatial epidemiology: an emerging (or reemerging) discipline. Trends Ecol Evol 2005; 20: 328-36. DOI: $10.1016 /$ j.tree.2005.03.009.

2.- Keesing F, Holt R D, Ostfeld R S. Effects of species diversity on disease risk. Ecol Lett 2006; 9: 485-98. DOI: 10.1111/j.14610248.2006.00885.x

3.- Keesing F. Effects of Ecosystems on Disease. En: Ostfeld R, Keesing F, Eviner V editors. Infectious Disease Ecology. Effects of Ecosystems on Disease and of Disease on Ecosystems. New Jersey: Princeton University Press; 2008. P. 9-12.

4.- Enria D A, Briggiler A M, Feuillade M R. An overview of the epidemiological, ecological and preventive hallmarks of Argentine haemorrhagic fever (Junin virus). Bull Inst Pasteur 1998; 96: 103-14.

5.- Maiztegui J I. Clinical and epidemiological patterns of Argentine hemorrhagic fever. Bull. World Health Organ 1975; 52: 567-75.

6.- Maiztegui J I, Fernández N J, Damilano A J. Efficacy of immune plasma in treatment of Argentine hemorrhagic fever and association between treatment and late neurological sindrome. Lancet 1979; 8154: 1216-7.

7.- Enria D A, Maiztegui J I. Antiviral treatment of Argentine hemorrhagic fever. Antivir Res 1994; 23: 23-31.

8.- Enria D A, Feuillade M R, Levis S, Briggiler A M, Ambrosio A M, Saavedra M C, et al. Impact of vaccination of a high risk population for Argentine hemorrhagic fever with a live attenuated Junin virus vaccine. En: Saluzzo JF, Dodet B. editors. Factors in the Emergence and Control of Rodent-Borne Viral Diseases (Hantaviral and Arenaviral Diseases), Éditions Scientifiques et Medicales Elsevier SAS; 1999. P. 273-80.

9.- Vanella M M, González LE, Paglini A, Márquez J. Evidencias de laboratorio de actividad de virus Junin en el sudeste de Córdoba; Hipótesis sobre su epidemiología. El Día Medico 1964; 36: 290.

10.- Sabattini M S, Gonzales de Ríos L E, Díaz G, Vega V R. Infección natural y experimental de roedores con virus Junin. Medicina 1977; 37 : 149-59.

11.- Maiztegui J, Sabattini M. Extensión progresiva del área endémica de Fiebre Hemorrágica Argentina. Medicina 1977; 37: 162-6.

12.- Carballal G, Videla C, Merani M. Epidemiology of Argentine Hemorragic Fever. Eur J Epidemiol 1988; 4: 259-74.

13.- Mills J, Ellis B, McKee K, Calderón G, Maiztegui J, Nelson G, et al. A longitudinal study of Junin virus activity in the rodent reservoir of Argentine Hemorragic Fever. Am J Trop Med Hyg 1992a; 47: 749-63.

14.- Mills J, Ellis B, Childs J, Maiztegui J, CastroVázquez A. Reproductive characteristics of rodent assemblages in cultivated regions of central Argentina. J Mammal 1992b; 73: 51526.

15.- Ellis B, Mills J, Childs J, Muzzini M, Mc Kee $\mathrm{K} J \mathrm{~J}$, Enría D, et al. Structure and floristics of habitats associated with five rodent species in an agroecosystem in Central Argentina. J Zoo Soc London 1997; 243: 437-60.

16.- Kravetz F. Ecología de las comunidades de roedores involucradas en la Fiebre Hemorrágica Argentina. Tesis doctoral, Universidad de Buenos Aires, Buenos Aires, Argentina; 1978.

17.- Kravetz F, Polop J. Comunidades de roedores en agroecosistemas del Departamento Río Cuarto, Córdoba. Ecosur 1983; 10: 1-10.

18.- de Villafañe G, Kravetz F, Donadio O, Percich R, Knechen L, Torres M, Fernández N. Dinámica de las comunidades de roedores en agroecosistemas pampásicos. Medicina (Bs. As.) 1977; 37: 128-38

19.- Mills J, Ellis B, McKee K, Calderón G, Maiztegui J, Ksiazek T, et al. Junín virus activity in rodents from endemic and nonendemic loci in central Argentina. Am J Trop Med Hyg 1991a; 44: 589-97.

20.- Bonaventura S M, Bellocq M I, Kravetz F O. Selección de hábitat por roedores en campos de cultivo. Un estudio experimental. Physis (Bs. As.) Sec. C 1988; 47: 1-5.

21.- Kravetz F O, de Villafañe G. Poblaciones de roedores en cultivo de maíz durante las etapas de madurez y rastrojo. Historia Natural 1981; 1: 213-32.

22.- Zuleta G A. Estrategias de historia de vida en el ratón de pastizal pampeano Akodon azarae. Tesis Doctoral. Universidad de Buenos Aires, Ciudad Autónoma de Buenos Aires, Argentina. 1989.

23.- Cittadino E A, De Carli P, Busch M, Kravetz F O. Effects of food supplementation on rodents in winter. J Mammal 1994; 75: 446-53.

24.- Bilenca D N, Kravetz F O. Seasonal variations in microhabitat use and feeding habits of the pampas mouse Akodon azarae in agroecosystems of central Argentina. Acta Theriol 1998; 43: 195-203.

25.- Busch M, Kravetz F O, Percich R E, Zuleta G A. Propuesta para un control ecológico de la Fiebre Hemorrágica Argentina (FHA) a través del manejo del hábitat. Medicina (Buenos Aires) 1984; 44: 34-40

26.- Mills J, Ellis B, McKee K, Maiztegui J, Childs J. Habitat associations and relative densities of rodent populations in cultivated areas of central Argentina. J Mammal 1991b; 72: 470-9.

27.- Busch M, Miño M, Dadon J, Hodara K. Habitat selection by Calomys musculinus (Muridae, Sigmodontinae) in crop areas of the pampean region, Argentina. Ecología Austral 2000; 10 : 15-26.

28.- Crespo J, Sabattini M, Piantanida M, de Villafañe G. Estudios ecológicos sobre roedores silvestres. Observaciones sobre densidad, reproducción y estructura de las comunidades de roedores silvestres en el sur de la provincia de Córdoba. Ministerio de Bienestar Social, Secretaría Estado de Salud Pública, Buenos Aires; 1970, p 1-45.

29.- Calderón G. Desarrollo de indicadores de riesgo de contraer la Fiebre Hemorrágica Argentina, por medio de roedores que actúan como reservorio de los Arenavirus en Argentina. Tesis doctoral. Universidad Nacional del Litoral, Rosario, Argentina; 2004.

30.- Polop J, Calderón G, Feuillade R, García J, EnríaD, Sabattini M. Spatial variation in abundance of the Junin virus host in endemic and non-endemic Argentine Hemorragic Fever zones. Austral Ecol 2007; 32: 245-53. https:// doi.org/10.1111/j.1442-9993.2007.01679.x

31.- Polop F, Provensal C, Scavuzzo M, Lanfri M, Calderón G, Polop J. On the relationship between the environmental history and 
the epidemiological situation of Argentine

Hemorrhagic Fever. Ecol Res 2008; 23: 217-25.

32.- Piacenza MF. Abundancia de Calomys musculinus, variables ambientales y diferencias en la incidencia de Fiebre Hemorrágica Argentina. Tesis Doctoral. Universidad Nacional de Río Cuarto, Río Cuarto, Argentina; 2012.

33.- Calderón G, Feuillade M R, García J, Brigiler M, Polop J, EnríaD, Sabattini M. Características de las comunidades y poblaciones de pequeños roedores en áreas epidémicas y no epidémicas de Fiebre Hemorrágica Argentina (FHA). Fundación Alberto J. Roemmers, Anales 1995/1998; 1995, p. 118-30.

34.- Mills J, Childs J. Ecologic studies of rodent reservoirs: their relevance for human health. Emerg Infect Dis 1998; 4: 529-37.

35.- Mills J, Amman B R, Glass G E. Ecology of hantaviruses and their hosts in North America. Vector-Borne Zoonotic Dis 2010; 10: 563-74. DOI: $10.1089 /$ vbz.2009.0018

36.- Ostfeld R S, Keesing F. Biodiversity and disease risk: the case of Lyme disease. Conserv Biol 2000; 14: 722-8.

37.- Loreau M, Naeem S, Inchausti P, Bengtsson $\mathrm{J}$, Grime J P, Hector A, et al. Biodiversity and ecosystem functioning: current knowledge and future challenges. Science 2001; 294: 804-8. DOI: $10.1126 /$ science. 1064088

38.- Johnson P T J, Thieltges D W. Diversity, decoys and the dilution effect: how ecological communities affect disease risk. J Exp Biol 2010; 213: 961-70. doi: 10.1242/jeb.037721

39.- Morales M A, Calderón G E, Riera L M, Ambrosio A M, Enría D A, Sabattini M S. Evaluation of an enzyme-linked immunosorbent assay for detection of antibodies to Junin virus in rodents. J Virol
Methods 2002; 103: 57-66.

40.- Sikes R S, Gannon W I and The Animal Care and Use Committee of the American Society of Mammalogists. Guidelines of the American Society of Mammalogists for the use of wild mammals in research. J Mammal 2011; 92 : 235-53.

41.- Mills J N, Childs J E, Ksiazek T G, Peters C J, Velleca W M. Methods for Trapping and Sampling Small Mammals for Virologist Test. U.S. Department of Health and Human Services. Public Health Service. Center for Disease Control and Prevention. Atlanta: Georgia; 1995.

42.- Gannon L W, Sikes R S and The Animal Care and Use Committee of the American Society of Mammalogists. Guidelines of the American Society of Mammalogists for the use of wild mammals in research. J Mammal 2007; 88: 809-23.

43.- Di Rienzo J A, Casanoves F, Balzarini M G, González L, Tablada M, Robledo C W. Infostata versión 2012. Grupo Infostat, FCA, Universidad Nacional de Córdoba, Argentina; 2012. URL http://www.infostat.com.ar

44.- Polop J J, Martínez R L, Torres M P. Distribución y abundancia de poblaciones de pequeños roedores en la zona de embalse de Río Tercero, Córdoba. Historia Natural 1985; 5 : 33-44.

45.- Polop J, Sabattini M. Rodent abundance and distribution in habitats of agrocenosis in Argentina. Stud Neotrop Fauna E 1993; 28: 47-55.

46.- Simone I, Cagnacci F, Provensal C, Polop J. Environmental determinants of the small mammal assemblage in an agroecosystem of central Argentina: The role of Calomys musculinus. Mamm Biol 2010; 75: 496-509. DOI: 10.1016/j.mambio.2009.12.002.
47.- Mills J N. Regulation of rodent-borne viruses in the natural hosts: Implications for human diseases. Arch Virol 2005; 19: 45-57.

48.- Busch M, Hodara K. Uso y selección de hábitat y competencia interespecífica en roedores sigmodontinos de la región Pampeana. En: Polop J J, Busch M editors. Biología y ecología de pequeños roedores en la región Pampeana de Argentina. Enfoques y perspectivas. Primera Edición. Córdoba: Universidad Nacional de Córdoba; 2010. p. 147-171.

49.- Sabattini M, Contigiani M S. Ecological and biological factors influencing the maintenance of arenaviruses in nature, with special reference to the agent of Argentinean Haemorrhagic Fever. En: International Symposium on Tropical Arboviruses and Haemorrhagic Fevers. Río de Janeiro. Brasil: Academia Brasileira de Ciencias editores; 1982. P. 251-262.

50.- Mills J, Ellis B, Childs J, Mckee K Jr, Maiztegui J, Peters C et al. Prevalence of infection with Junin virus in rodent population of endemic area of AHF. Am J Trop Med Hyg 1994; 51: 554-62.

51.- Vitullo A D, Hodara V L, Merani M S. Effect of persistent infection with Junin virus on growth and reproduction of its natural reservoir, Calomys musculinus. Am J Trop Med Hyg 1987; 37: 663-9.

52.- Weissenbacher M C, Calello M A, Carballal G, Planes N, de la Vega M T, Kravetz F O. Actividad del virus Junín en humanos y roedores de áreas no endémicas de la provincia de Buenos Aires. Medicina 1985; 45: 263-8.

53.- Mills J N, Calderón G E, Ellis B A, McKee K T, Ksiazek T G, Barrera Oro J G, et al. Nuevas observaciones de la infección de roedores por el virus Junin dentro y fuera de la zona endémica de la Fiebre Hemorrágica Argentina. Medicina 1991c; 51: 519-23. 